\title{
An investigation into tool dynamics adaptation for chatter stability enhancement in the turning of flexible workpieces
}

\author{
Kaibo $\mathrm{Lu}^{1 *}$, Fengshou $\mathrm{Gu}^{2}$, Andrew Longstaff ${ }^{2}$, Guoyan $\mathrm{Li}^{1}$ \\ 1. College of Mechanical and Vehicle Engineering, Taiyuan University of Technology, Shanxi 030024, \\ China
}

2. School of Computing and Engineering, University of Huddersfield, Huddersfield, HD1 3DH, UK

*Corresponding author. Email: 1vkaibo@tyut.edu.cn, lvkaibo4@163.com; Tel: +86-139-0341-8795

\begin{abstract}
It seems a universally accepted doctrine that chatter resistance of a machining system can be improved with increasing stiffness of its components. However, the viewpoint that the tool stiffness reduction would be beneficial to cutting stability of flexible components has been demonstrated by the compliant tool-workpiece chatter model. This paper presents a comprehensive investigation of the dynamic interaction between the tool and the workpiece during turning operations and its effect on the cutting stability. Following the formulation of the chatter model, the effect of the coupling dynamics of the cutting system on the limiting depth of cut $(d o c)$, a conservative but reliable indicator for evaluating the stability level of the machining process, is highlighted. It is shown that stability can be enhanced by judicious increase of the tool flexibility and/or the workpiece damping. Also, an inflection point generally exists on the cutting position-dependent limiting doc stability curve, revealing that the stability appears to be unchanged once the stiffness of the tool or workpiece is increased to a certain degree. As a result, the analysis results lay the foundation of a tool dynamics adaptation (TDA) approach to machining chatter control. It suggests an adaptive adjustment of the tool dynamics to the machined workpiece to enhance stability. The proposed approach was validated through turning experiments, in which the tool shank was installed parallel to the length of the flexible workpiece. The experimental results have shown an effective extension of the chatter-free cutting margin when tuning dynamics of the compliant tool-workpiece system. Given the reality that there is no absolutely rigid workpiece or tool in industrial applications, the proposed chatter control strategy can be adopted as a generic approach for the turning or boring processes.
\end{abstract}

Keywords: Flexible workpieces; Stability; Chatter suppression; Tool dynamics adaptation. 


\section{Introduction}

Flexible parts like long slender beams or thin-walled components are widely utilized in automotive and aerospace industry. Machining such parts is a challenging process because of their low rigidity. One of the major difficulties in turning flexible workpieces is the tendency to chatter, jeopardizing surface finish and process stability. A number of treatments have been investigated to suppress or mitigate chatter vibrations, thus enhancing the machining stability. Generally, those measures can be categorized as either passive or active methods $[1,2]$.

The passive strategies include the conventional approach which provides additional support devices, such as steady or follower rests [3, 4], to improve stiffness of the workpiece for machining operations. Another method focuses on prediction of chatter stability regions using analytical methods $[5,6]$, discretization methods [7], or the Chebyshev collocation method [8]. Chatter-free cutting parameters can then be chosen to avoid the detrimental vibrations during machining. Along with optimization techniques [9], this method can increase process productivity with higher material removal rates. In addition, a great deal of effort has been done to develop various dynamic vibration absorbers [10, 11] or tuned mass dampers $[12,13]$ to suppress chatter and to improve machining stability. The advantages of the passive chatter control techniques are that they are relatively easy to implement and do not need external energy. However, their performance is often affected by uncertainties or time-variant attributes of the machining processes.

In the active methods, the chatter vibrations are actively controlled by condition monitoring of the machining process and by executing rapid and effective changes in the process [14]. The method to continuously vary the spindle speed so as to disrupt the regenerative effect during chatter build-up has been attracting massive attention thanks to its simplicity in operation. The form of the speed adjustment can be sinusoidal $[15,16]$ or quasi-random [17]. A more complex approach is to vary the structural stiffness of the machine tool by the use of smart materials like electro-rheological fluids [18], magnetorheological fluids [19], and piezoelectric stack actuators [20]. These methods aim at modifying modal characteristics of the machine tool structure online during machining, to disrupt the modulation of the current tool vibrations with the previous tool vibrations and thereby suppressing chatter instability. Although the processes studied in [18-20] are for elimination of vibration coming from the boring or milling tool, the same approach could be applied to that derived from turning the flexible workpiece under investigation.

When it comes to improvement of stability through changing stiffness for machining flexible parts, the first natural thought is to enhance the stiffness of the workpiece $[3,4,21]$. Because, ideally, the optimal condition for machining processes is that both the tool and the workpiece are rigid so that cutting forces fail to result in any relative motion between them during operation. It seems to be a universally accepted doctrine that chatter resistance of a tool-workpiece machining system can be improved by increasing 
stiffness of its components. If the increase of the workpiece stiffness is not convenient, probably, few people accept the idea that decreasing tool stiffness could also be beneficial to the cutting stability, which, as stated in [22], is counterintuitive.

In the past decade, scholars began to take the compliance of both the workpiece and the cutting tool into account when modelling the chatter behaviour [22-26]. The tool was generally modelled as a timeinvariant single degree of freedom (SDOF) system, while the workpiece was regarded as a time-variant SDOF model [23-25] or a finite element model [22, 26]. The simulation results of the compliant toolworkpiece chatter model demonstrated that tool stiffness reduction would be favourable to the turning stability of low-rigidity workpieces. However, these results were theoretical and were not supported by experimental verification in these investigations. The approach was reportedly verified by experiments in $[14,27,28]$. Unfortunately, the comprehensive or quantitative study of the tool dynamics variation on chatter stability was still absent in the literature.

In this paper, based on the compliant tool-workpiece chatter model, a new perspective is explored on chatter resistance in turning of flexible workpieces. The rest of the paper is organized as follows: Section 2 formulates the SDOF and the compliant chatter models sequentially and compares their corresponding stability criterion expressions. In Section 3 simulation studies were performed to analyse the influence of dynamic parameters including stiffness, damping and eigenfrequency of the cutting system on the chatter stability. After that, rigorous experiments were carried out to demonstrate the effectiveness of the proposed method in Section 4. Finally, conclusions are given.

\section{Turning chatter modelling and its stability analysis}

The turning process is a synergic and dynamic interaction between a cutting tool and a rotating workpiece. Machining chatter is due to the interaction of the machine tool structure and the cutting process. The vibration response characteristics of the tool and workpiece at any given cutting position directly affect the process quality. Here, two different chatter models suitable for flexible workpiece turning are to be constructed for comparison.

\subsection{SDOF chatter model}

In turning of a flexible part, it is reasonable to assume that the tool is rigid and the workpiece is represented by a SDOF system at a specific cutting position. And only the motion normal to the cutting surface is considered since the radial oscillation of the flexible workpiece contributes mainly to the chattering regeneration effect during cutting. The corresponding equation of motion is a delayed differential equation as follows,

$$
m_{w} \ddot{x}_{w}+c_{w} \dot{x}_{w}+k_{w} x_{w}=K_{c} d\left[x_{w}(t-\tau)-x_{w}(t)\right]
$$


where $m_{w}, c_{w}, k_{w}$ are the equivalent mass, damping coefficient, and stiffness of the machined component respectively, $K_{c}$ is the cutting coefficient related to machining conditions, $d$ is the depth of cut (doc), $\tau=60 / N$ is the time delay where $N$ is the spindle rotation speed.

Transforming Eq. (1) into the frequency domain by the Laplace transform and rearranging leads to

$$
\left[\frac{1}{Q(s)}+G_{w}(s)\right] X_{w}(s)=0
$$

where $Q(s)=K_{c} d\left(1-e^{-\tau s}\right)$ is the dynamic stiffness function of the turning operation associated with the regenerative effect in cutting, $G_{w}(s)=\frac{1}{m_{w} s^{2}+c_{w} s+k_{w}}$ is the receptance transfer function of the lumpedmass workpiece system, and $X_{w}(s)$ is the displacement in the frequency domain. As a result, the chatter stability can be determined by the characteristic equation of the model as follows,

$$
\frac{1}{Q(s)}+G_{w}(s)=0
$$

The equation formulates the relationship between the cutting process and the structural dynamics of the cutting system for chatter stability analysis. Let $s=j \omega$, the limiting doc or width of cut for the absolute chatter stability criterion can be achieved according to Tlusty's law[1, 29]

$$
d_{\lim }=-\frac{1}{2 K_{c} \operatorname{Re}\left\{G_{w}(\omega)\right\}_{\min }}
$$

where $\operatorname{Re}\left\{G_{w}(\omega)\right\}$ represents the real part of the transfer function $G_{w}(\omega)$. It means that the minimum of $\operatorname{Re}\left\{G_{w}(\omega)\right\}$ determines the value of the $d_{\text {lim }}$. Furthermore, the analytical expression of $d_{\text {lim }}$ is deduced by differentiating $\operatorname{Re}\left\{G_{w}(\omega)\right\}$ with respect to the chatter frequency $\omega$, which reads

$$
d_{\lim }=\frac{2 k_{w} \zeta_{w}\left(1+\zeta_{w}\right)}{K_{c}}
$$

where $\zeta_{w}$ is the damping ratio of the workpiece. On the basis of Eq. (5), the stability of a turning operation can be evaluated conservatively. If the $d o c$ used in the operation has $d \leq d_{\text {lim }}$, the cutting system is absolutely stable. On the other hand, for an adopted $d o c d$, if the stiffness of the system is $k \leq K_{c} d / 2 \zeta_{w}\left(1+\zeta_{w}\right)$, the cutting is prone to being unstable.

\subsection{Compliant tool-workpiece chatter model}

During practical machining operations, both the workpiece and the tool suffer from deformation and vibration to varying degrees. Thus, without loss of generality the compliance between the workpiece and the tool should be included when modelling chatter phenomena. 


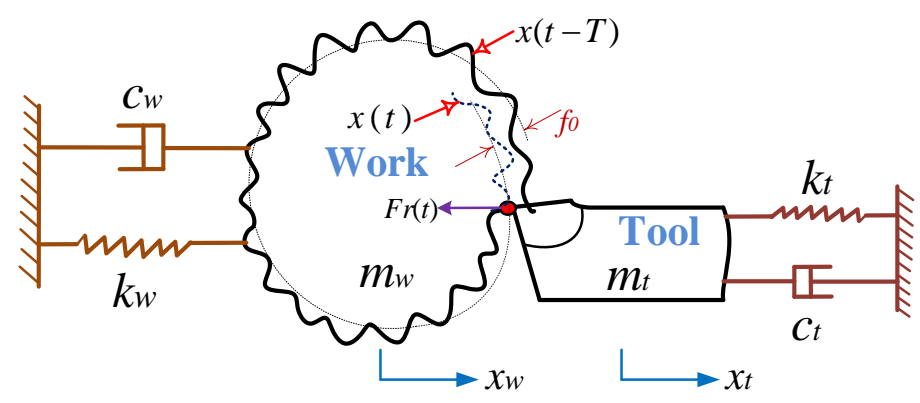

Fig. 1 Compliant tool-workpiece chatter model

Similar to [24], this study regards the interaction between the workpiece and the cutting tool as a twodegree-of-freedom (2DOF) lumped-mass system, as shown in Fig. 1. The tool-workpiece model can be expressed with two differential equations as

$$
\begin{aligned}
& m_{t} \ddot{x}_{t}+c_{t} \dot{x}_{t}+k_{t} x_{t}=F_{r}(t) \\
& m_{w} \ddot{x}_{w}+c_{w} \dot{x}_{w}+k_{w} x_{w}=-F_{r}(t)
\end{aligned}
$$

where the subscripts $t$ and $w$ refer to the tool and workpiece respectively, $F_{r}(t)=K_{c} d\left[\left(x_{t}(t-\tau)-x_{w}(t-\tau)\right)-\left(x_{t}(t)-x_{w}(t)\right)\right]$ is the dynamic component of the radial cutting force acting on the workpiece, $m_{t}, c_{t}, k_{t}$ are the equivalent mass, damping coefficient, and stiffness of the cutting tool, respectively.

After rewriting Eqs. (6) and (7) in matrix form, the 2DOF chatter model reads

$$
[M]\{\ddot{X}\}+[C]\{\dot{X}\}+[K]\{X\}=\{F(t)\}
$$

where $[M]_{2 \times 2}=\left[\begin{array}{ll}m_{t} & \\ & m_{w}\end{array}\right],[C]_{2 \times 2}=\left[\begin{array}{ll}c_{t} & \\ & c_{w}\end{array}\right],[K]_{2 \times 2}=\left[\begin{array}{ll}k_{t} & \\ & k_{w}\end{array}\right],\{X(t)\}_{2 \times 1}=\left[\begin{array}{c}x_{t}(t) \\ x_{w}(t)\end{array}\right]$, $\{F(t)\}=-K_{c} d A_{0}(\{X(t)\}-\{X(t-\tau)\})$, and $A_{0}=\left[\begin{array}{cc}1 & -1 \\ -1 & 1\end{array}\right]$.

Transforming Eq. (8) into the frequency domain obtains the characteristic equation of the compliant tool-workpiece model as

$$
\operatorname{det}\left([M] s^{2}+[C] s+[K]+A_{0} Q(s)\right)=0
$$

Rearranging the determinant of Eq. (9) yields

$$
\frac{1}{Q(s)}+\left(G_{t}(s)+G_{w}(s)\right)=0
$$

where $G_{t}(s)=\frac{1}{m_{t} s^{2}+c_{t} s+k_{t}}$ is the receptance transfer function of the tool system, $Q(s)$ and $G_{w}(s)$ are the same as in Section 2.1. Here, let $G(s)=G_{t}(s)+G_{w}(s)$, which is defined as the receptance transfer 
function of the tool-workpiece system. According to Eqs. (3) and (4), the expression of $d_{\lim }$ for the 2DOF chatter model in the frequency domain can be obtained as

$$
d_{\lim }=-\frac{1}{2 K_{c} \operatorname{Re}\left\{G_{t}(\omega)+G_{w}(\omega)\right\}_{\min }}
$$

Substituting the expressions of $G_{t}(\omega)$ and $G_{w}(\omega)$ into $G(\omega)$ and rearranging the terms yields the expression of the real part of $G(\omega)$ as

$$
\operatorname{Re}\{G(\omega)\}=\frac{1}{k_{w}} \frac{1-\lambda_{w}^{2}}{\left(1-\lambda_{w}^{2}\right)^{2}+\left(2 \zeta_{w} \lambda_{w}\right)^{2}}+\frac{1}{k_{t}} \frac{1-\lambda_{t}^{2}}{\left(1-\lambda_{t}^{2}\right)^{2}+\left(2 \zeta_{t} \lambda_{t}\right)^{2}}
$$

where $\lambda_{w}=\omega / \omega_{n w}, \lambda_{t}=\omega / \omega_{n t}, \omega_{n w}$ and $\omega_{n t}$ are the natural frequencies of the workpiece and the tool respectively, and $\zeta_{t}$ is the damping ratio of the tool.

Physically, the limiting doc $d_{\lim }$ and the cutting coefficient $K_{c}$ are positive values, hence the minimum of $\operatorname{Re}\{G(\omega)\}$ in Eq. (11) needs to be negative. So, according to Eq. (12), the chatter frequency $\omega$ should be greater than the smaller one of the two eigenfrequencies $\omega_{n w}$ and $\omega_{n t}$ at least, that is, $\omega>\min \left(\omega_{n}, \omega_{n w}\right)$. Suppose $\omega_{n w}<\omega<\omega_{n t}$, the first term at the right side of Eq. (12) corresponding to the real part of $G_{w}(\omega)$ is negative but the second term corresponding to the real part of $G_{t}(\omega)$ is positive. In comparison with Eq. (4), it is known that the negative value of $\operatorname{Re}\{G(\omega)\}$ will increase, which in turn results in an increased positive $d_{\lim }$ according to Eq. (11). On the other hand, if $\omega>\max \left(\omega_{n w}, \omega_{n t}\right)$, the two terms at the right side of Eq. (12) are both negative values. Compared with Eq. (4), it can be found that the negative value of $\operatorname{Re}\{G(\omega)\}$ will be smaller and thus lead to a decreased $d_{\lim }$. Consequently, it can be inferred that the inclusion of the selective compliance of the tool in chatter modelling leads to finding a new approach to enhancing the chatter stability of the machining system.

In addition, it can be inferred that the $d_{\lim }$ for the absolutely stable cutting will decrease to the half of the value referred to the SDOF model when the tool and the workpiece have identical dynamic parameters. Obviously, if the tool or the workpiece is much stiffer than its counterpart, the compliant tool-workpiece chatter model will be reduced to an SDOF model. These inferences are to be demonstrated below.

\section{Numerical simulation for stability prediction}

This section focuses on the influence of the structural dynamics of the machining system to gain an understanding of the degree of the interaction between the tool and workpiece on the level of stability. In a turning operation, the workpiece is rotated and the cutting tool is traversed parallel to the axis of the workpiece. The moving contact of the workpiece and the tool induces a position-dependent response 
to the cutting force. Therefore, to evaluate the dynamic behaviour of the system the process stability along the entire cutting path needs to be explored.

\subsection{Position-dependent stability lobe diagram}

As described in the previous section, the chatter model consists largely of two sub-systems: the cutting tool dynamics at the tool tip and the flexible workpiece dynamics at the cutting position. Thus, during a turning operation, the SDOF model of the tool can be regarded as a time-invariant system, whereas the modelled SDOF workpiece is a time-variant system due to the non-uniform stiffness distribution along its length. To simulate this scenario, the stiffness of the workpiece model is set to be a specific value which varies at a specified interval. For simplicity, other modal parameters are assumed to be constant. In this way, the chatter behaviour can be examined with moving tool cutting position along the workpiece during each cutting pass. Table 1 summarizes the baseline modal parameters of the tool and the workpiece for simulation and comparison.

Table 1 Modal parameters of the tool and workpiece for simulation

\begin{tabular}{cccc}
\hline Parameters & $\begin{array}{c}\text { Stiffness } \\
(\mathrm{N} / \mathrm{m})\end{array}$ & Damping ratio & $\begin{array}{c}\text { Natural frequency } \\
(\mathrm{Hz})\end{array}$ \\
\hline Cutting tool & $k_{t}=0.8 \times 10^{7}$ & $\zeta_{t}=0.0265$ & $\omega_{n t}=1614$ \\
Workpiece & $2 \times 10^{6} \leq k_{w} \leq 9 \times 10^{6}$ & $\zeta_{w}=0.0272$ & $\omega_{n w}=414$ \\
Cutting coefficient & $K_{c}=614 \mathrm{MPa}$ & & \\
\hline
\end{tabular}

For a specified cutting location along the flexible workpiece, at which $k_{w}=6 \times 10^{6} \mathrm{~N} / \mathrm{m}$, the stability lobe diagram with different tool stiffness is calculated using the Nyquist criterion as applied to Eqs. (3) and (10) for the SDOF and 2DOF models respectively. As shown in Fig. 2, the 2DOF model with $k_{t}=0.8 \times 10^{7} \mathrm{~N} / \mathrm{m}$ produces a larger margin of stability than the SDOF model, whereas the stability of the machining process with $k_{t}=0.6 \times 10^{7} \mathrm{~N} / \mathrm{m}$ becomes decreased in comparison with that with a rigid tool. Additionally, the peaks of the real part of the receptance $G(\omega)$ for the two models are compared, as presented in Fig. 3. It is seen that the case of $k_{t}=0.6 \times 10^{7} \mathrm{~N} / \mathrm{m}$ holds the lowest negative value of $\operatorname{Re}\{G(\omega)\}$, while the case of $k_{t}=0.8 \times 10^{7} \mathrm{~N} / \mathrm{m}$ has the highest value of $\operatorname{Re}\{G(\omega)\}$. Accordingly, it can be proved that judicious reduction of the tool stiffness would be helpful for cutting stability. Also, if the tool is stiff enough, the stability lobes by the two chatter models are getting close, indicating that the compliant tool-workpiece model is reduced to the SDOF model, thus the 2DOF chatter model provides greater generality. 


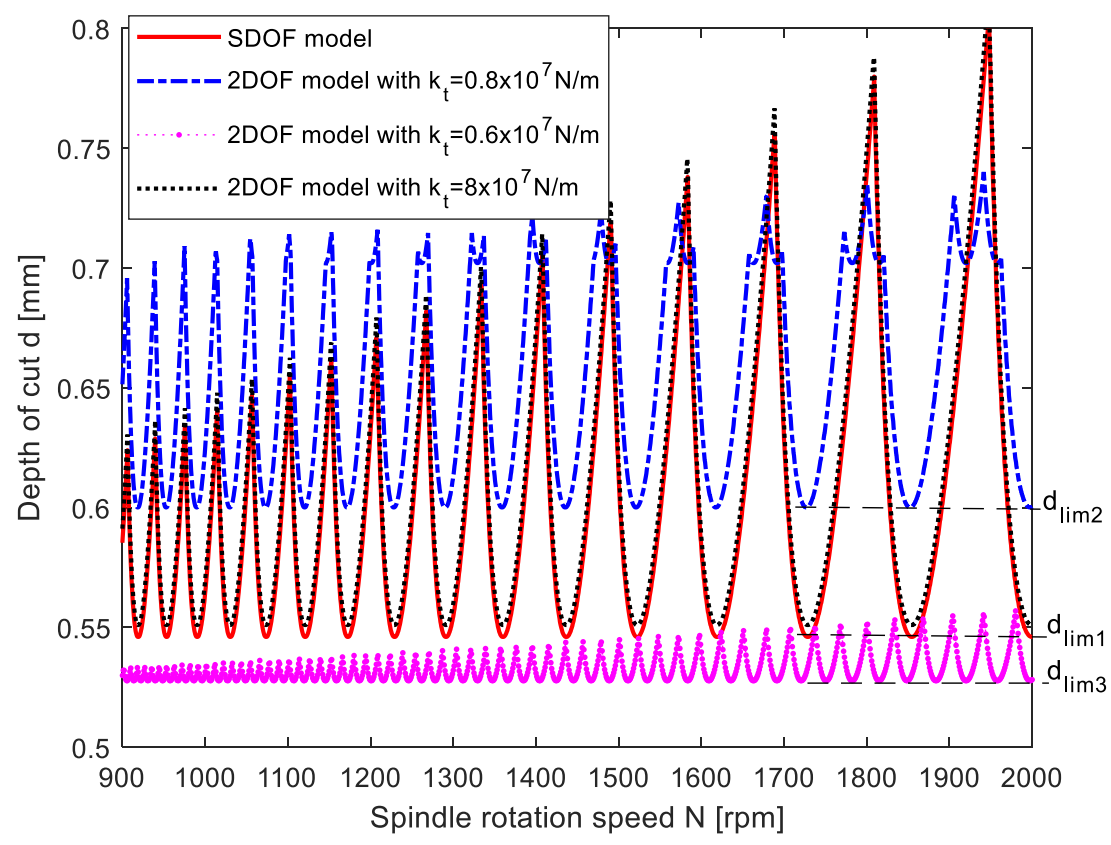

Fig.2 Stability comparison of the SDOF and 2DOF models at a cutting position with $k_{w}=6 \times 10^{6} \mathrm{~N} / \mathrm{m}$

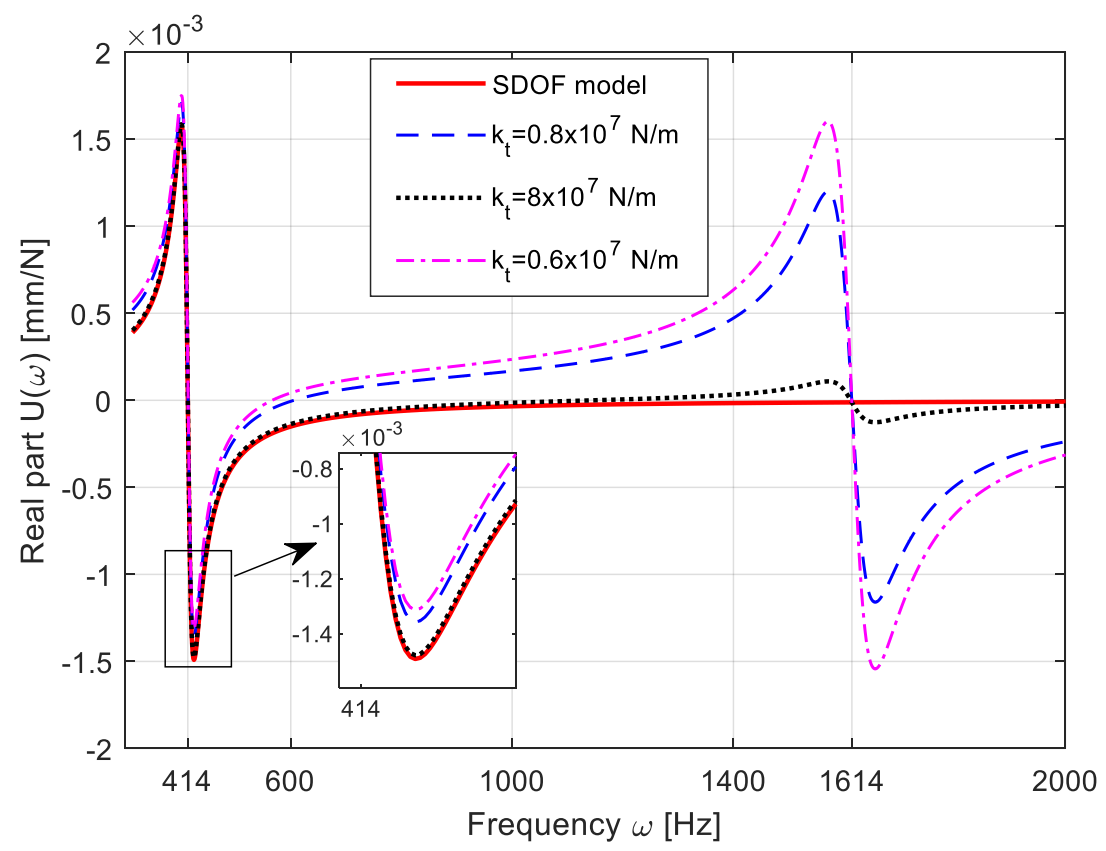

Fig. 3 Effect of tool stiffness on the real part of the receptance of the cutting system with $k_{w}=6 \times 10^{6} \mathrm{~N} / \mathrm{m}$

For a given tool, the feed movement during a turning operation causes $k_{w}$ to change with respect to cutting points, as a result of which the corresponding stability lobes are varying. By means of the compliant tool-workpiece model, the position-dependent stability lobes can be drawn, as seen in Fig. 4. It can be concluded that for a given tool, the cutting stability usually deteriorates with a reduction in the workpiece stiffness. 


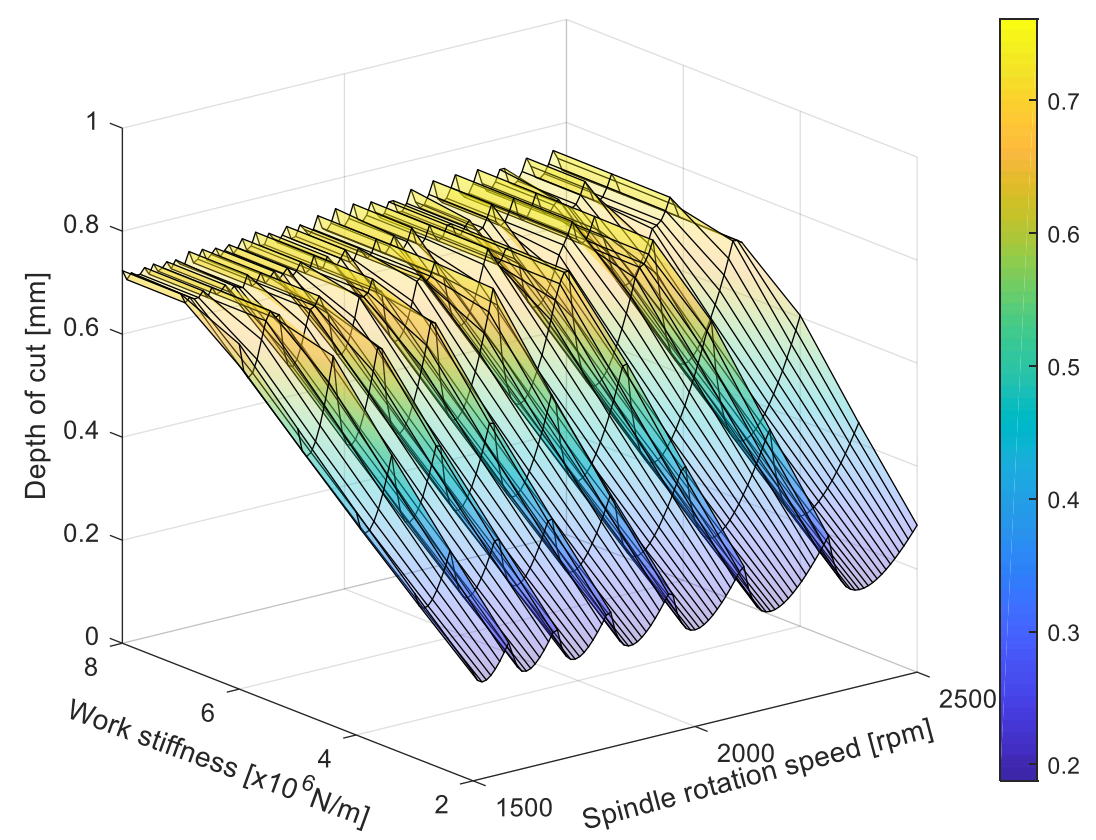

Fig.4 Position-dependent stability charts for the compliant tool-workpiece system

Furthermore, under the practical fixture conditions the turned workpiece normally has a non-uniform distribution of stiffness along its length, thus the chatter onset is associated with the ongoing cutting point on the workpiece. For a known $d o c, d$, the chatter onset location can be predicted with the following implicit equation, which is derived based on Eqs. (11) and (12)

$$
f\left(k_{w}(z), \zeta_{w}, \omega_{n w}, k_{t}, \zeta_{t}, \omega_{n t}, K_{c}, \omega\right)-d=0
$$

where the function $f(\mathrm{~g})$ denotes the right side of Eq. (11), $z$ is the cutting position along the axis of the workpiece, the dynamic parameters $\left(k_{w}(z), \zeta_{w}, \omega_{n w}\right)$ at the cutting point for the workpiece and that of ( $\left.k_{t}, \zeta_{t}, \omega_{n t}\right)$ at the tool tip for the tool can be identified via experimental modal techniques, the cutting coefficient can be experimentally estimated by the cutting force acquisition or the derivation $K_{c}=2 k_{w} \zeta_{w}\left(1+\zeta_{w}\right) / d_{\lim }$ based on Eq. (5), and the critical chatter frequency $\omega$ corresponding to the minimum of the system receptance can be calculated using numerical methods. Generally, the chatter onset location has a nonlinear relationship with the depth of cut. When the chatter frequency is $\omega_{n w}<\omega<\omega_{n t}$, for the same $d_{\text {lim }}$ the dynamic model with a compliant tool implies a higher workpiece compliance at the chatter onset point, in comparison with that by the sole workpiece model with a stiff tool cutting.

\subsection{Effect of stiffness on chatter stability}

Fig. 5 demonstrates the influence of the stiffness of the tool and workpiece on $d_{\text {lim }}$ which is regarded as an indicator for conservative but reliable evaluation of the cutting stability in this study. For a given cutting tool, meaning that $k_{t}$ is constant, it is seen that $d_{\lim }$ generally decreases with an increase of the workpiece flexibility, which explains the difficulty of turning a flexible part. Also, it can be inferred 
that when the $d o c, d$, configured for a turning pass is no less than any position-dependent limiting depths of cut, chatter vibrations are likely to arise at the cutting point where the workpiece stiffness corresponds to $d_{\text {lim }}$ being equal to $d$.

It can be seen that reducing the tool stiffness, counterintuitively, but supporting the modelling in literature [22-28], could stabilize the process of turning a flexible workpiece. Note that it does not mean that simply lowering the tool stiffness will increase the $d_{\lim }$, such as the case of $k_{t}=0.2 \times 10^{7} \mathrm{~N} / \mathrm{m}$ (the dashed black line with triangle markers) in Fig. 5. In this case, the tool mode becomes dominant in vibration of the cutting system.

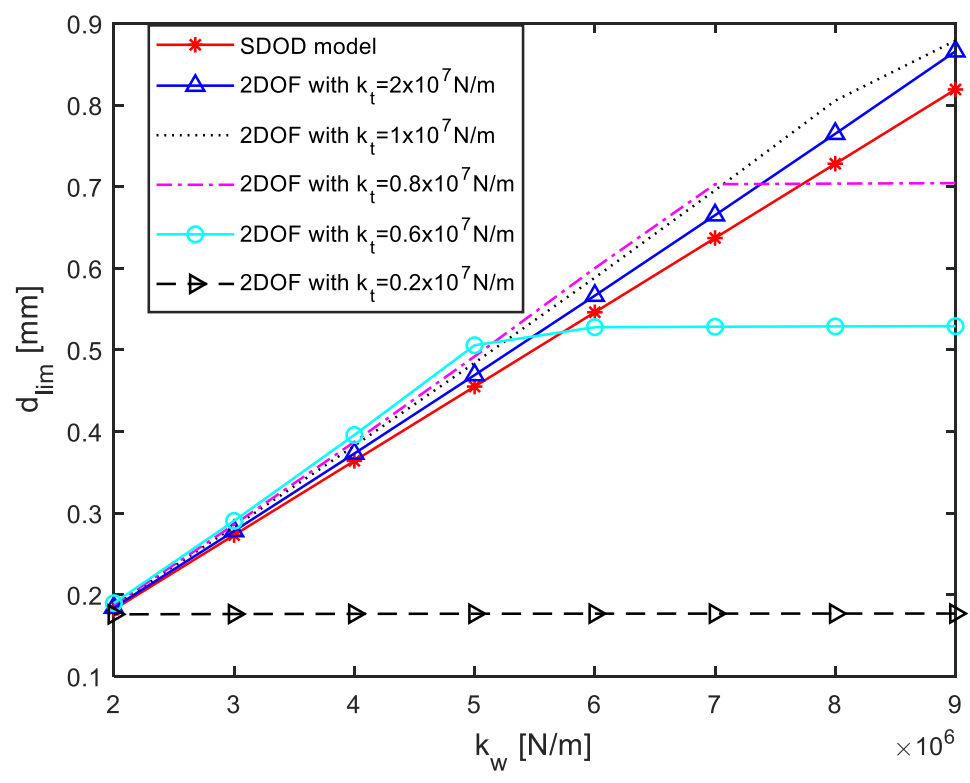

Fig.5 Effect of the tool stiffness on the limiting depth of cut

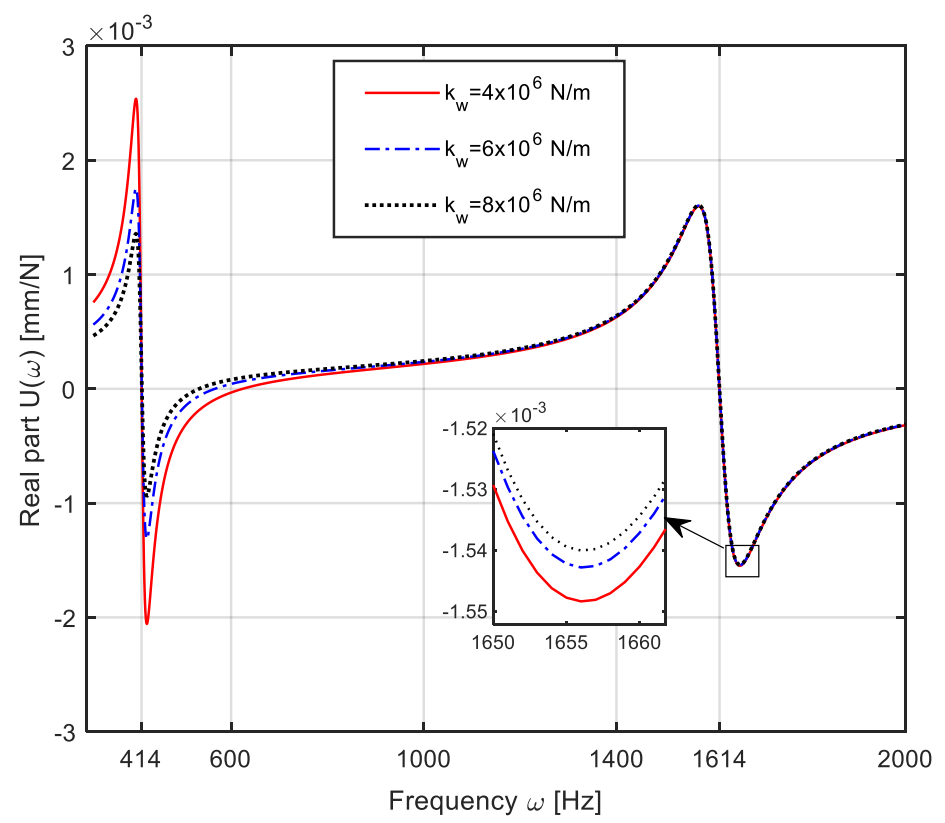

Fig.6 Effect of workpiece stiffness on the real part of the cutting system receptance with $k_{t}=0.6 \times 10^{7} \mathrm{~N} / \mathrm{m}$ 
In addition, it can be seen in Fig. 5 that for the case of $k_{t}=0.6 \times 10^{7} \mathrm{~N} / \mathrm{m}, d_{\lim }$ remains unchanging when the workpiece stiffness is larger than $6 \times 10^{6} \mathrm{~N} / \mathrm{m}$. It means that there is an inflection point on the limiting doc curve (also seen in Fig. 4), beyond which there is no further effect on the stabilization of the process by increasing workpiece stiffness. This can be further understood by presenting the receptance transfer function $G(\omega)$ of Eq. (12) in Fig. 6. The minimal real part of $G(\omega)$ of the compliant workpiece-tool system is shifted and located around the eigenfrequency of the tool with the increase of workpiece stiffness, indicating that the receptance of the tool contributes most to $G(\omega)$ and that the chatter frequency gets close to the eigenvalue of the tool.

\subsection{Effect of damping and eigenfreqency on chatter stability}

To explore and compare the effect of damping on the cutting stability of the flexible workpiece, the damping ratios of the workpiece and the tool are doubled and halved, respectively, as shown in Table 1. In contrast to the relative insensitivity of the tool damping, it is shown that increasing the damping of the workpiece could be advantageous to machining stability, especially in the difficult-to-cut region where the workpiece exhibits high flexibility, as illustrated in Fig. 7(a). Also, it is seen that $d_{\text {lim }}$ is decreased by half in comparison with the SDOF model when the dynamic parameters of the compliant tool are equal to the workpiece's at each cutting position. Apparently, this combination is not yet the worst matching relation of the tool and the workpiece for machining instability. The effect of the eigenfrequency of the tool on the chatter stability is described in Fig. 7(b). It can be seen that the eigenfrequency of the system seems to have minor influence on $d_{\lim }$ of the cutting system compared to the stiffness and the damping. However, it is noted that when the eigenfrequency of the tool and the workpiece is close then the chatter stability tends to be reduced dramatically. The reason is that the identical eigenfrequencies simultaneously make the two terms on the right side of Eq. (12) negative, lowering the value of $\operatorname{Re}\{G(\omega)\}$ and destabilizing the operation. Corresponding to Fig. 7, Fig. 8 provides typical real parts of the receptance of the machining system with its damping and eigenfrequency varying separately.
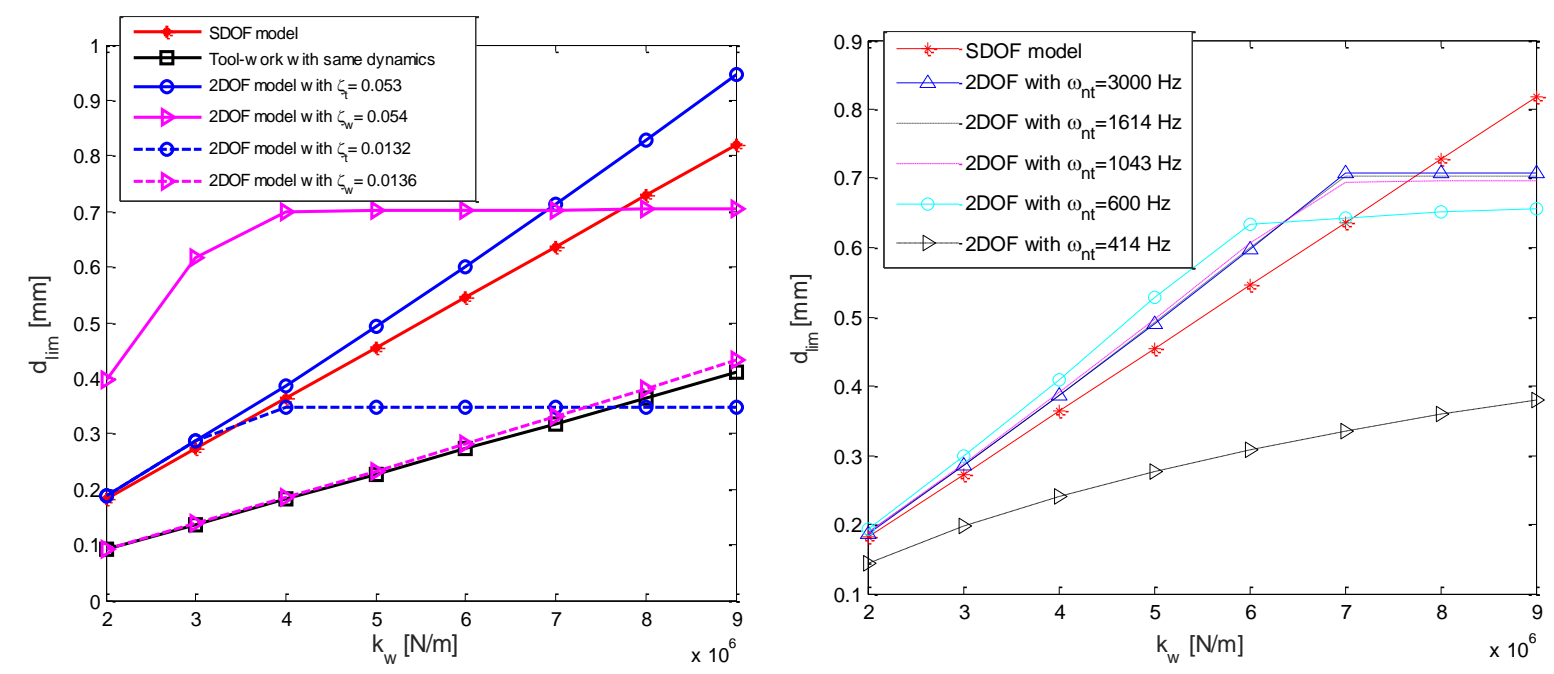
Fig. 7 Effect of damping (a) and eigenfrequency (b) on the limiting depth of cut

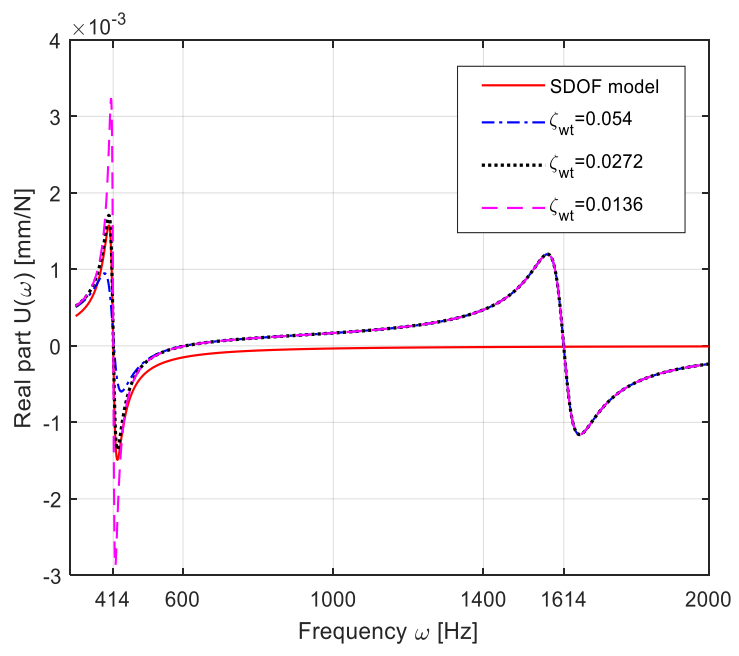

(a)

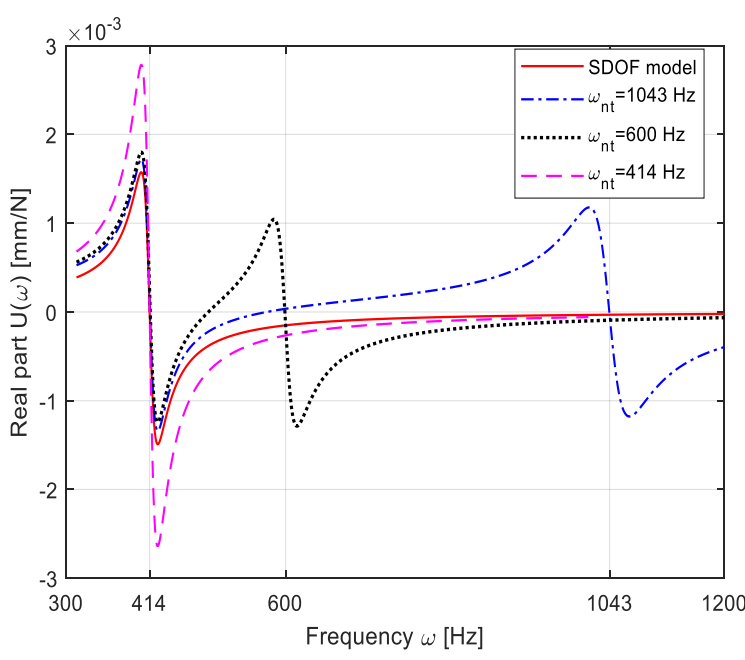

(b)

Fig. 8 Effect of damping (a) and eigenfrequency (b) on the real part of the cutting system receptance

Mathematically, provided that other cutting conditions are unvarying, there could be the optimal dynamic characteristics for the tool to adapt to the workpiece. Optimization techniques can be used to determine the optimal dynamic parameters on the basis of Eqs. (11) and (12). In summary, this result motivates further investigation into a tool dynamics adaptation (TDA) strategy for improving chatter stability. That is, adequately selecting or adjusting the tool dynamic parameters so as to match the machined workpiece will enhance the cutting stability.

\section{Experimental evaluation and discussion}

\subsection{Test setup}

This section deals with experimental evaluation of the proposed TDA strategy for reducing machining chatter. The experimental setup is given in Fig. 9. The experiments were conducted on a CK6136S horizontal lathe with the power of $5.5 \mathrm{~kW}$, where the workpiece was clamped by chuck at one end and free at the other. Unlike conventional configuration of a turning operation [14, 27, 28], the shank of the cutting tool was installed parallel to the axis of the workpiece. Meanwhile, to reduce the effect of the type-B chatter or cross Frequency Response Function (FRF) by the vibration in the tangential direction $[26,29,30]$, the width of the tool shank in the $X$ direction was designed to be $2 \mathrm{~mm}$ thinner than its height in the $Y$ direction, as seen in Fig. 10. The merit of this design lies in the convenience of changing the tool dynamics in $X$-axis by adjusting its overhang. 

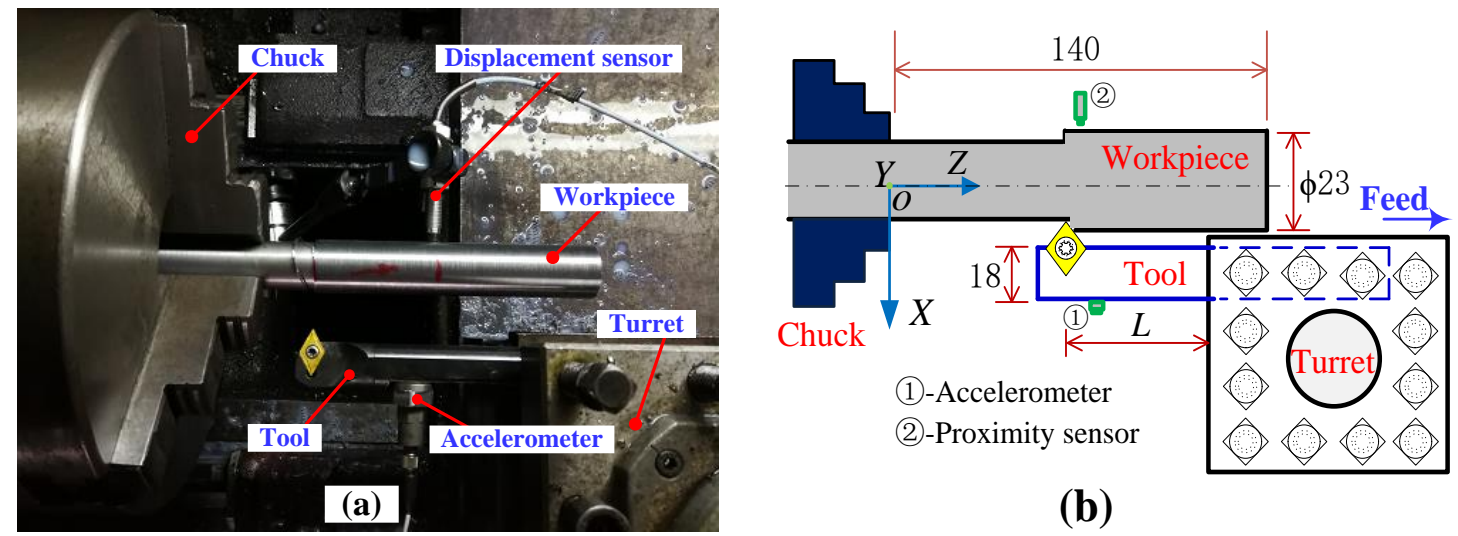

(b)

Fig. 9 Experimental setup: (a) Illustrative photo; (b) Schematic diagram.

A neutral cutting tool with a rectangular cross section with height $20 \mathrm{~mm}$ and width $18 \mathrm{~mm}$ was used. The compatible carbide insert of DCMT11T304 has a nose angle $55^{\circ}$, nose radius $0.4 \mathrm{~mm}$, and clearance angle $7^{\circ}$, respectively. The cutting edge angle remained $62.5^{\circ}$ during machining. All the test bars had a nominal length of $200 \mathrm{~mm}$ and diameter of $23 \mathrm{~mm}$ and were made of 1045 steel. The material has the Young's modulus $E=2.06 \times 10^{5} \mathrm{MPa}$ and the density $\rho=7850 \mathrm{~kg} / \mathrm{m}^{3}$. A portable data acquisition system, CoCo-80, was used to record the measured signals.

Two kinds of experiments were performed. Firstly, static stiffness measurements and force-hammer tests were carried out to obtain the modal parameters of the tool and the workpiece [31]. Secondly, turning trials were conducted to observe the influence of the variation in tool dynamics on the dynamic behaviour of the system. According to the chatter lasting inference in [5], it is known that prediction of the chatter onset location is only feasible if the stability level of the cutting system decreases as the tool feeds. To this end, the turret was set to move from the chuck towards the free side in the turning experiments. For an operation, apart from the coolant implementation to minimize the influence of cutting heat, one fresh cutting tool was utilized for each test bar to eliminate the tool wear effect on the dynamic performance of the system. The designed conditions for the tests are summarized in Table 2 .

Table 2 Test conditions for compliant tool-workpiece chatter model.

\begin{tabular}{cccccc}
\hline Case & $\begin{array}{c}\text { Tool overhang } L \\
(\mathrm{~mm})\end{array}$ & $\begin{array}{c}\text { Depth of cut } d \\
(\mathrm{~mm})\end{array}$ & $\begin{array}{c}\text { Spindle speed } N \\
(\mathrm{rpm})\end{array}$ & $\begin{array}{c}\text { Feedrate } v \\
(\mathrm{~mm} / \mathrm{rev})\end{array}$ & $\begin{array}{c}\text { Bar diameter } \\
\text { and length } \\
(\mathrm{mm})\end{array}$ \\
\hline 1 & 35 & $0.6 / 0.75 / 0.9$ & 910 & 0.15 & $23 / 200$ \\
2 & 55 & $0.6 / 0.75 / 0.9$ & 910 & 0.15 & $23 / 200$ \\
3 & 75 & $0.6 / 0.75 / 0.9$ & 910 & 0.15 & $23 / 200$ \\
\hline
\end{tabular}

\subsection{Modal parameter identification}

At first, a sequence of marks equally spaced along the length of the object to be measured were labelled. Then a digital force gauge with a resolution of $0.1 \mathrm{~N}$ and a dial indicator with a resolution of 1 micrometre were utilized to measure the exerted force and the corresponding deflection in the $X$ 
direction at each marked point, as demonstrated in Fig. 10. After calculation, the stiffness of the object with respect to different positions or overhangs along its axis is achieved, as given in Fig. 11(a). As anticipated, it is clear that the stiffness increases with the reduced structural overhang. However, the physical stiffness values are generally lower than the analytical results predicted by using the idealized cantilevered model, revealing that the compliance of the work-holder (spindle/chuck) or tool-holder (turret) systems on dynamics of the tool and workpiece could be non-negligible. This observation is consistent with the experimental results in [32-34].

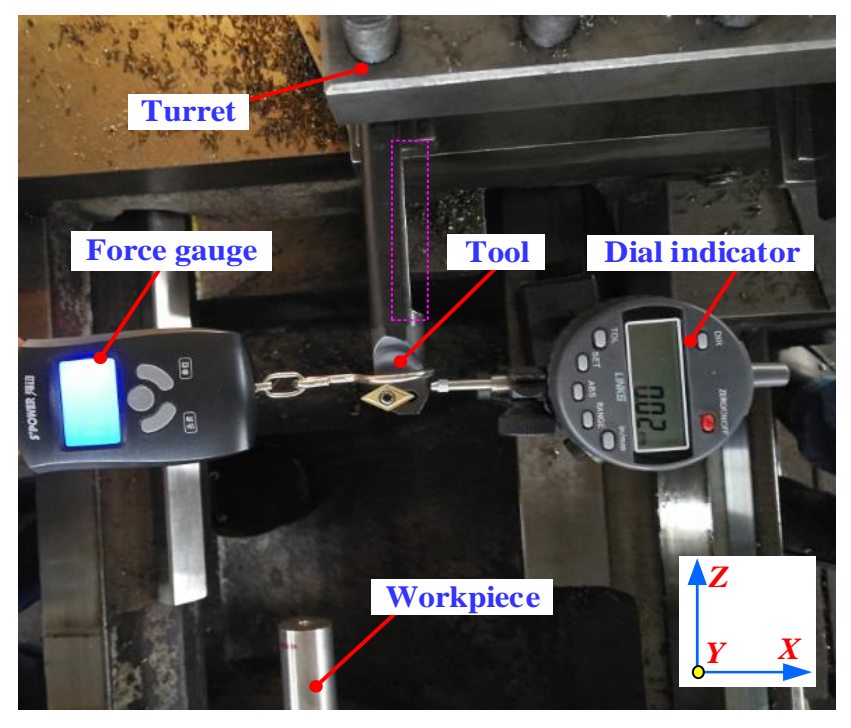

Fig. 10 Setup for the stiffness measurement

Additionally, the hammer tests were performed to achieve the natural frequency and damping ratio of the system. Two accelerometers were respectively attached to the tool shank and the workpiece to acquire the response to the impact. For the tool, the hammer impact and sensor acquisition point was near the tool-insert; for the workpiece, the impacts and responses at two different positions along its length were measured. Finally, the accelerance FRFs of the tool and the workpiece was determined, as shown in Fig. 11(b). It is noted that the accelerance FRF of the tool with overhang $L=35 \mathrm{~mm}$ is absent because it was hard to be excited by the hammer, which is a sign of high rigidity. By calculating the logarithmic decrement of the measured response, the damping ratios of the tool and the bar were estimated as $\zeta_{t}=0.0265$ and $\zeta_{w}=0.0272$, respectively. 


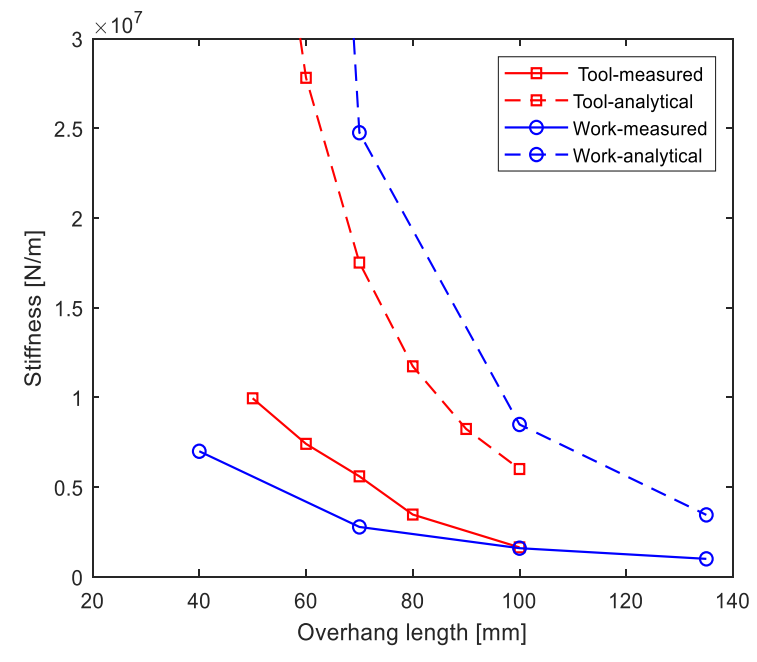

(a)

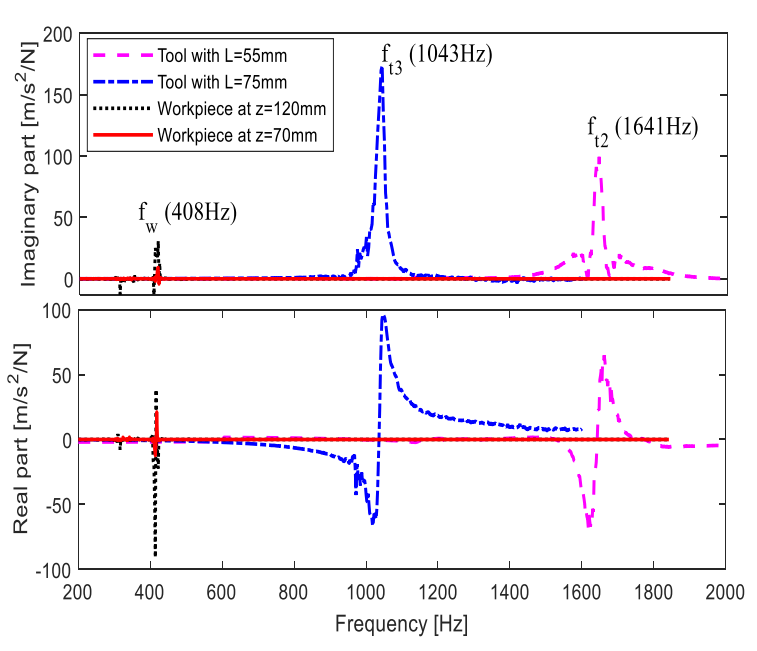

(b)

Fig. 11 Measured stiffness (a) and accelerance FRFs (b) of the tool and the workpiece.

Considering the relationship between the accelerance and receptance FRFs, that is, Accelerance $/\left(-\omega^{2}\right)=$ Receptance, the real parts of the receptance of the cutting tool and workpiece can be calculated indirectly, as shown in Fig. 12. It is seen that the peak in the real part of the workpiece receptance FRF increases with the measuring point furthest away from the chuck. This is attributed to the declining stiffness distribution along the workpiece, as shown in Fig. 11(a). Apparently, the tool receptance decreases with its overhang shortened.

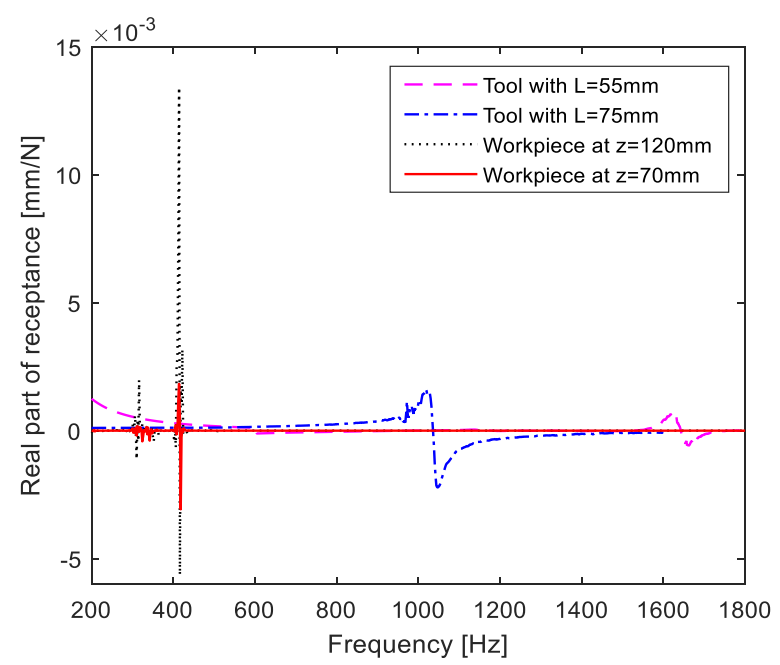

Fig.12 Real parts of the measured receptance FRFs of the separate tool and workpiece

Fig. 13 depicts the effect of the tool overhang on the receptance of the tool-workpiece system quantitatively. It can be seen the participation of the tool compliance could lead to an increased minimum peak of $\operatorname{Re}\{G(\omega)\}$ of the machining system. Relatively, the tool with overhang $\mathrm{L}=55$ may yield a higher stability level. It is seen that the negative peaks of the FRF of the 2DOF system register an approximately $10 \%$ increase at $z=70 \mathrm{~mm}$ but $4 \%$ increase at $z=120 \mathrm{~mm}$. Consequently, it can be 
inferred that for a cutting pass the stabilizing effect from the tool dynamics would be reduced progressively as the tool keeps travelling along the Z-axis direction in operation.

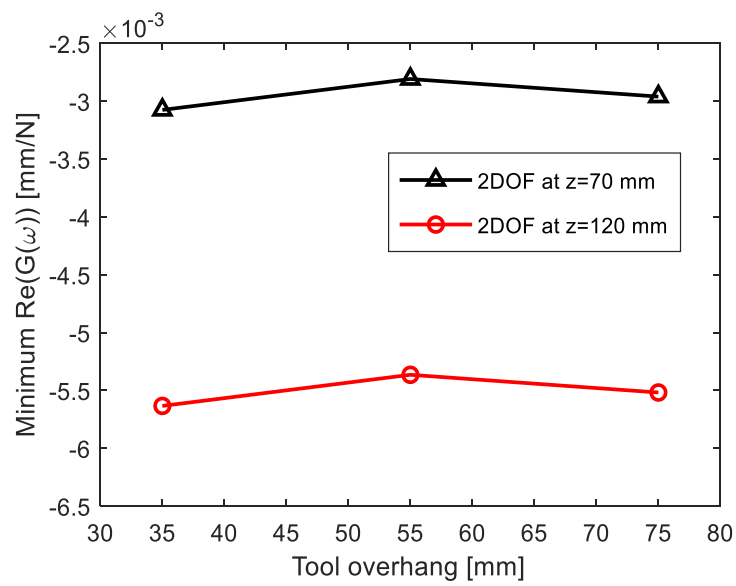

Fig. 13 Effect of tool overhangs on the real part of the receptance of the 2DOF model

\subsection{Machining tests}

In the machining experiments, an accelerometer was adhered to the shank of the tool to pick up the acceleration of the tool, and a non-contact sensor was supported by a magnetic stand which was fixed on the lathe bed to measure the displacement of the machined bar in the $X$ direction, as seen in Fig. 9 . The sample rate was set to $4096 \mathrm{~Hz}$.

During a turning operation, the cutting state was usually initially stable, with chatter initiating when the tool arrived at certain location along the workpiece. Thereafter, chatter, signified by enlarged amplitude of vibration, continued for the remainder of that run, as shown in Fig. 14. The effect was to create spiralshaped marks on the machined surface. As shown in Fig. 15(a), the dominant frequency from the workpiece was the spindle rotation frequency $f_{s}=15 \mathrm{~Hz}$. When chatter arose this induced vibration at the critical chatter frequency $f_{c}=392 \mathrm{~Hz}$. For the tool, the bandwidth of the acceleration signal turned from broad to narrow, the frequency $f_{c}$ and its harmonics dominating, as depicted in Fig. 15(b), where the machining conditions $d=0.9 \mathrm{~mm}$ and $L=75 \mathrm{~mm}$ were employed. It shows that during machining, the cutting tool or the workpiece that is not chattering is still vibrating. Also, it is interesting to note that the chatter frequency was a little lower rather than higher than the eigenfrequency of the workpiece $f_{w}=408 \mathrm{~Hz}$. The reason is probably that the centrifugal force caused by rotation of the free-ended workpiece subjected to cutting force resulted in reduction of the spindle bearing stiffness. This phenomenon is similar to the observation reported in [35] that the natural frequency of the milling spindle system reduced with cutting load effect. 


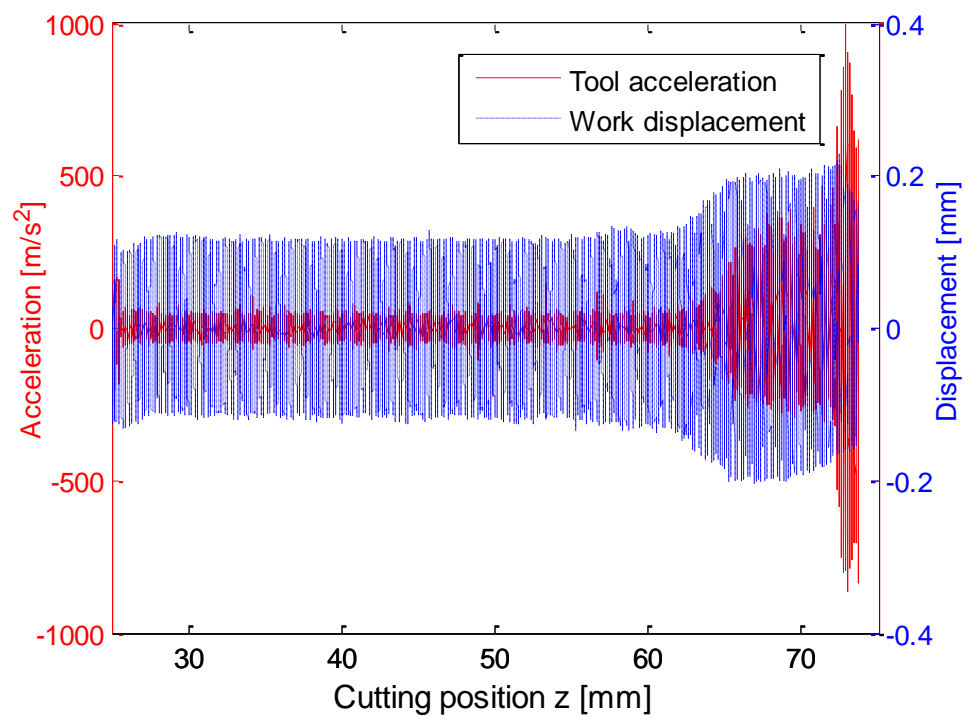

Fig. 14 Vibration signals of the tool and workpiece for a turning pass

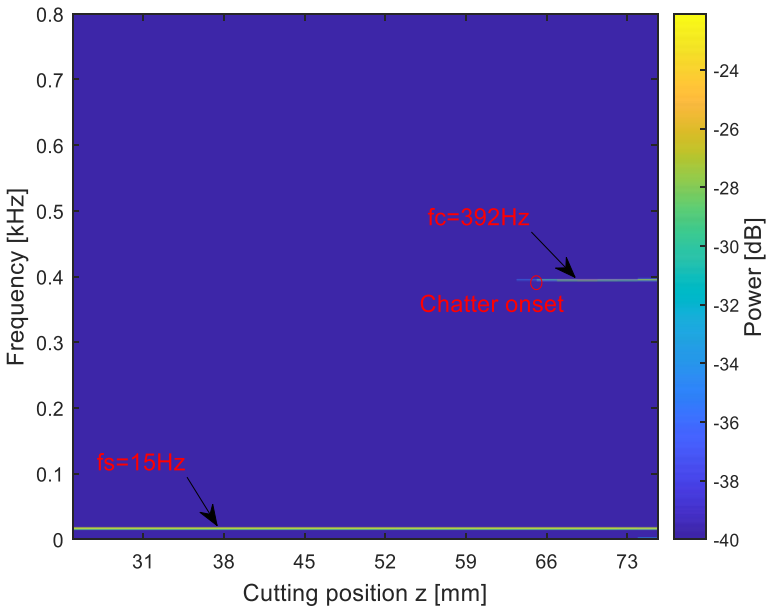

(a)

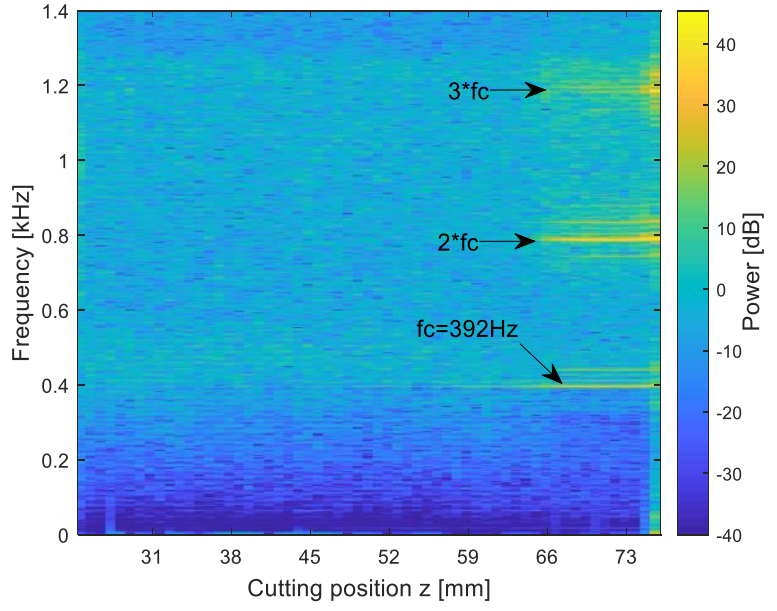

(b)

Fig. 15 Spectral transition of the workpiece displacement (a) and the tool acceleration (b) during the cutting 
(a)

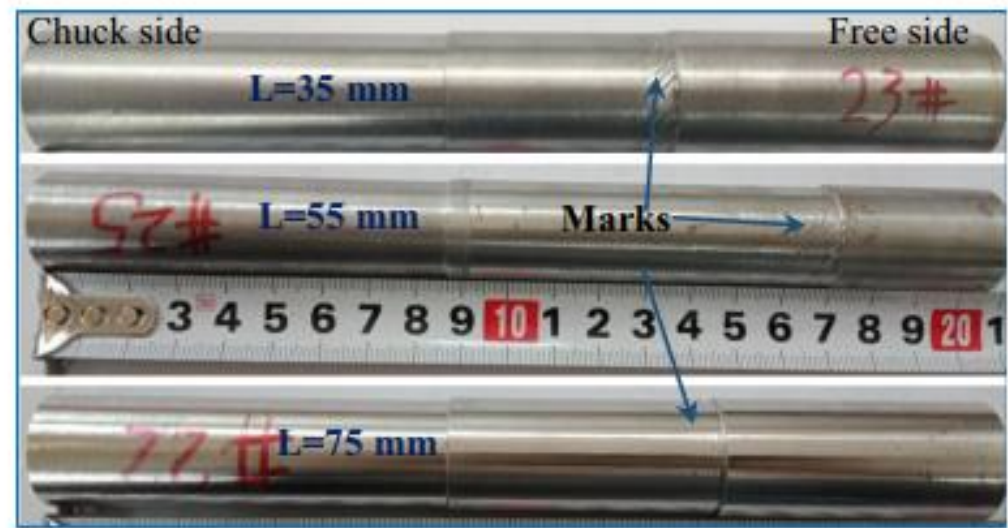

(b)

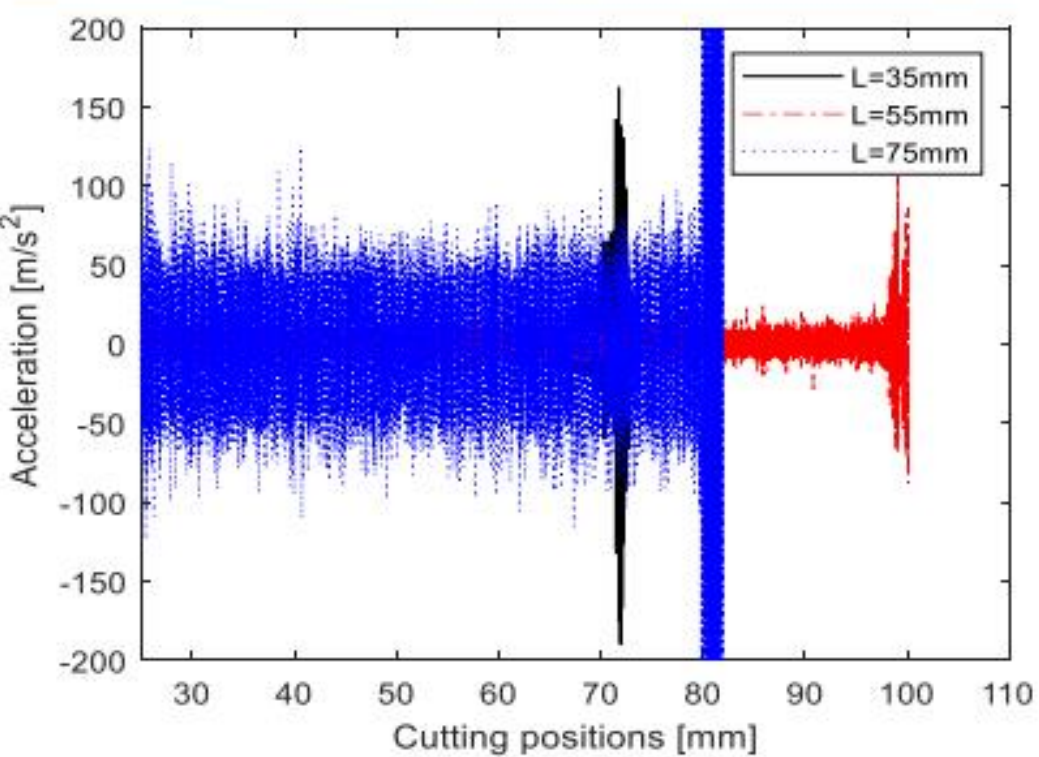

(c)

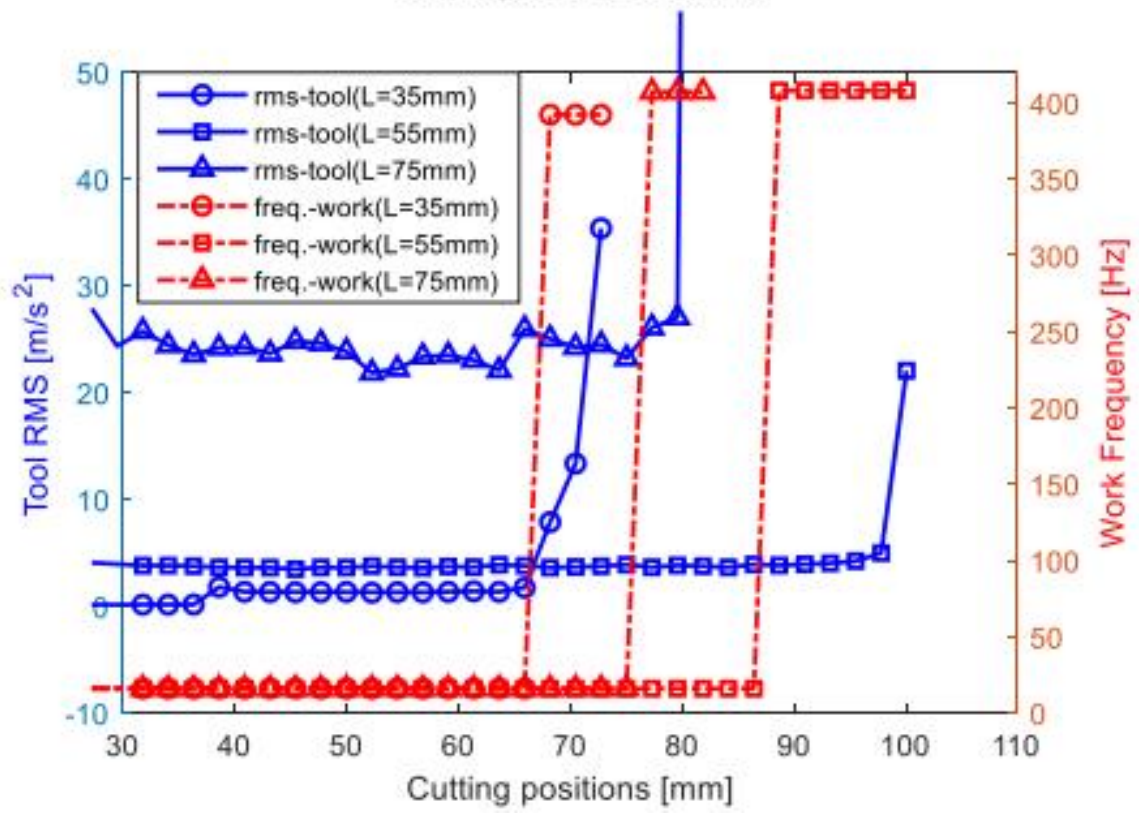

Fig. 16 Workpiece surface quality and vibration signals analysis: (a) The surface quality of the tested bars; (b) The acceleration signals of the tool; and (c) the position-dependent RMS and frequency. 
Fig. 16 is the representation of a set of machined surfaces along with signals analysis for different tool overhangs, where the same $d o c d=0.6 \mathrm{~mm}$ was adopted for each test bar and the overhang length of the workpiece originated from the jaw tip was kept $140 \mathrm{~mm}$ for all tests (see Fig. 9).

From Fig. 16(a), it is readily seen that the chatter onset location clearly varies with the adjustment of the tool shank overhangs. In comparison with the case of $L=35 \mathrm{~mm}$ that represents the rigid tool scenario, lengthening the overhang of the cutting tool, which is equivalent to reducing the tool stiffness, could delay the occurrence of chatter, thus prolonging the chatter onset location along the workpiece. However, it has also been observed that the longer tool did not mean the longer stable cutting state, such as the case of $L=100 \mathrm{~mm}$ presented in Fig. 17. In this case, the surface finish of the workpiece deteriorated once the tool tip started to contact and cut the workpiece, even though chatter has not fully developed at the beginning of the operation. On the contrary, when the tool overhang became shorter than $35 \mathrm{~mm}$, the chatter onset location was nearly the same as that of the case $L=35 \mathrm{~mm}$. The observations agree with the prior theoretical analysis and the experimental FRF results in Fig.13.

Correspondingly, the tool acceleration signals in Fig. 16(b) show that their amplitudes are increased with the tool overhang lengthened. The tool with $L=75 \mathrm{~mm}$ exhibits much larger amplitude and fluctuation than other two cases. Accordingly, the idea that a proper reduction of the tool stiffness in cutting flexible parts could improve the process stability can be explained from the perspective of energy consumption. The compliant tool vibrated and absorbed a part of the energy induced by the regenerative effect of machining operation, thus lowering the risk of chatter emergence of the flexible workpiece. However, if the flexibility of the tool is increased to a certain extent, its mode would dominate in vibration of the cutting system. If this is the case then the energy that the tool bears could make it vibrate intensely and even chatter, worsening the operation, as interpreted in Figs. 2 and 3.

Fig. 16(c) presents the calculated root mean square (RMS) of the tool acceleration and the dominant frequency of the workpiece displacement at different cutting positions. It is shown that the onset of chatter corresponds to the increased RMS of vibration in the time domain, while the dominant vibration frequency of the workpiece exhibits a shift in spectrum. Of the studied cases, the cutting stability benefitted most from the case of $L=55 \mathrm{~mm}$, in which the stable state was maintained until the tool arrived at the point of $Z=85 \mathrm{~mm}$. It is worth pointing out that the transition of the dominant frequency emerged earlier than the RMS did in this case. This phenomenon is likely attributed to the workpiece springback effect due to the low rigidity of the bar near its free end and the resulting retraction under cutting forces. This can be further evidenced by the scratch-like marks left on the bar surface, as seen in Fig. 16(a). 


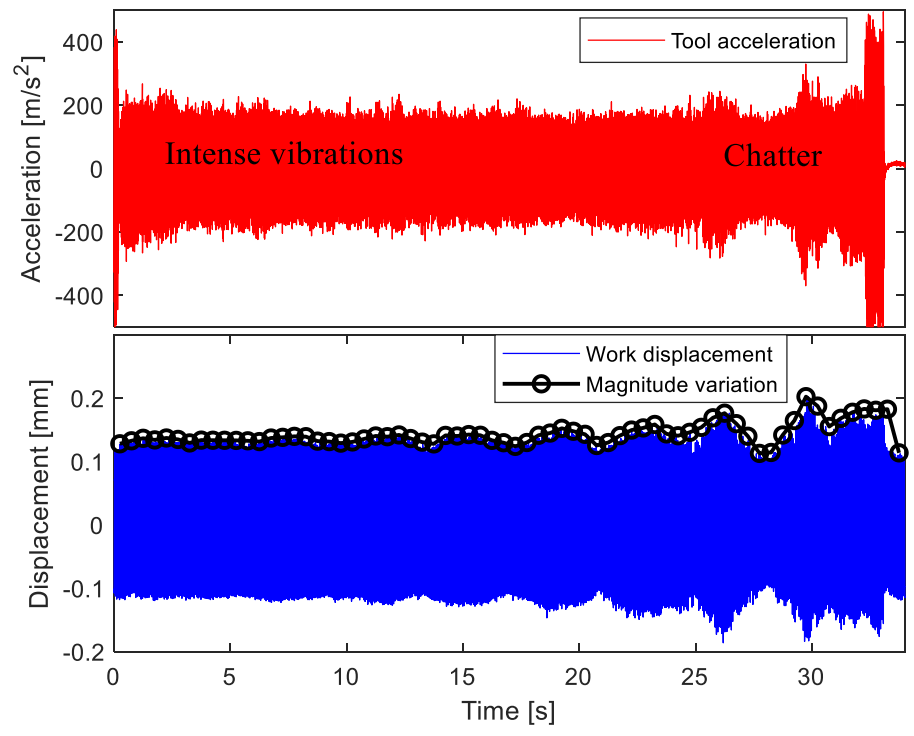

(a)

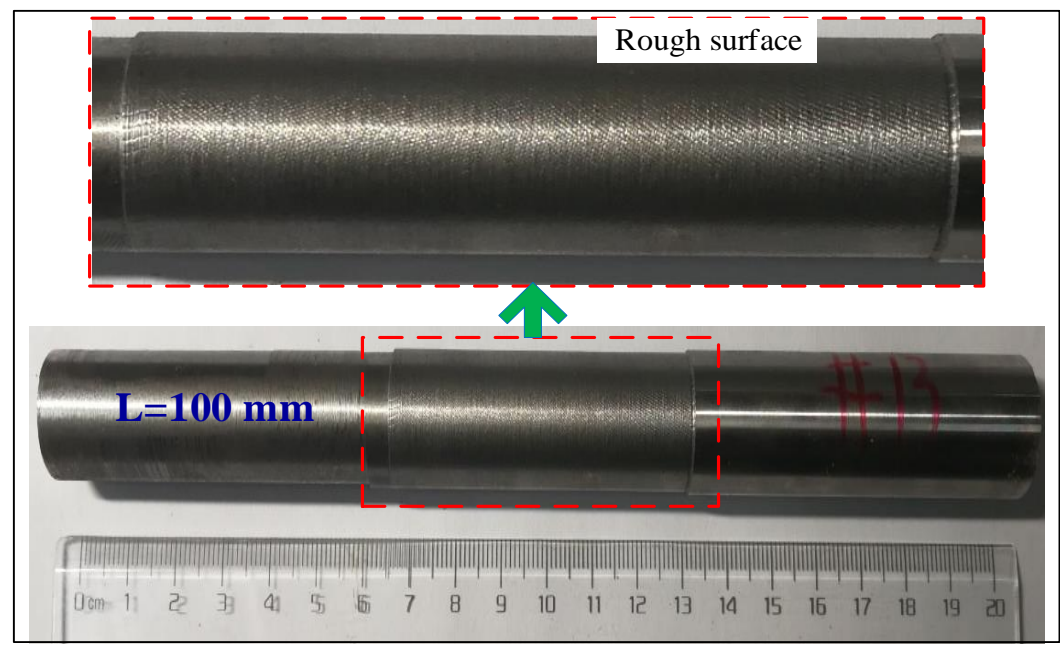

(b)

Fig. 17 Machining vibrations (a) and workpiece surface quality (b) with tool overhang $L=100 \mathrm{~mm}$

Fig. 18 presents the theoretical prediction and experimental measurements of the chatter onset locations with respect to various depths of cut. The theoretical calculation is from Eq. (13), in which the cutting coefficient is assumed constant and was calibrated in reference to the measured average chatter onset location under the conditions of $d=0.6 \mathrm{~mm}$ and $L=35 \mathrm{~mm}$. The equivalent eigenfrequencies and the damping ratios of the two sub-systems were obtained in the previous subsection and the positiondependent stiffness was determined by interpolating the measurements in Fig. 11(a) with a third order polynomial. The chatter frequency related to the spindle rotation speed was numerically estimated to be $428 \mathrm{~Hz}$, which is slightly higher than the measured eigenfrequency of the workpiece.

It is seen from Fig. 18 that the experimental onset values agree with the theoretical ones in terms of exhibiting a decreasing trend. However, they are generally higher than the predicted values. The average 
percentage error was around $10.74 \%$. This difference is mainly due to the effect of the nonlinear process damping induced by the machining operation, which leads to more improvement in the process stability. Using the same $d o c$, the cutting with the tool overhang $L=55$ was more likely to remain stable for longer. The average level of extension was up to $21.78 \%$ compared with that of utilizing the stiff tool, showing a significant improvement. This verifies that judiciously tuning the tool dynamics allows the chatter resistance in turning of flexible parts to be enhanced and thus confirmed the effectiveness of the TDA method.

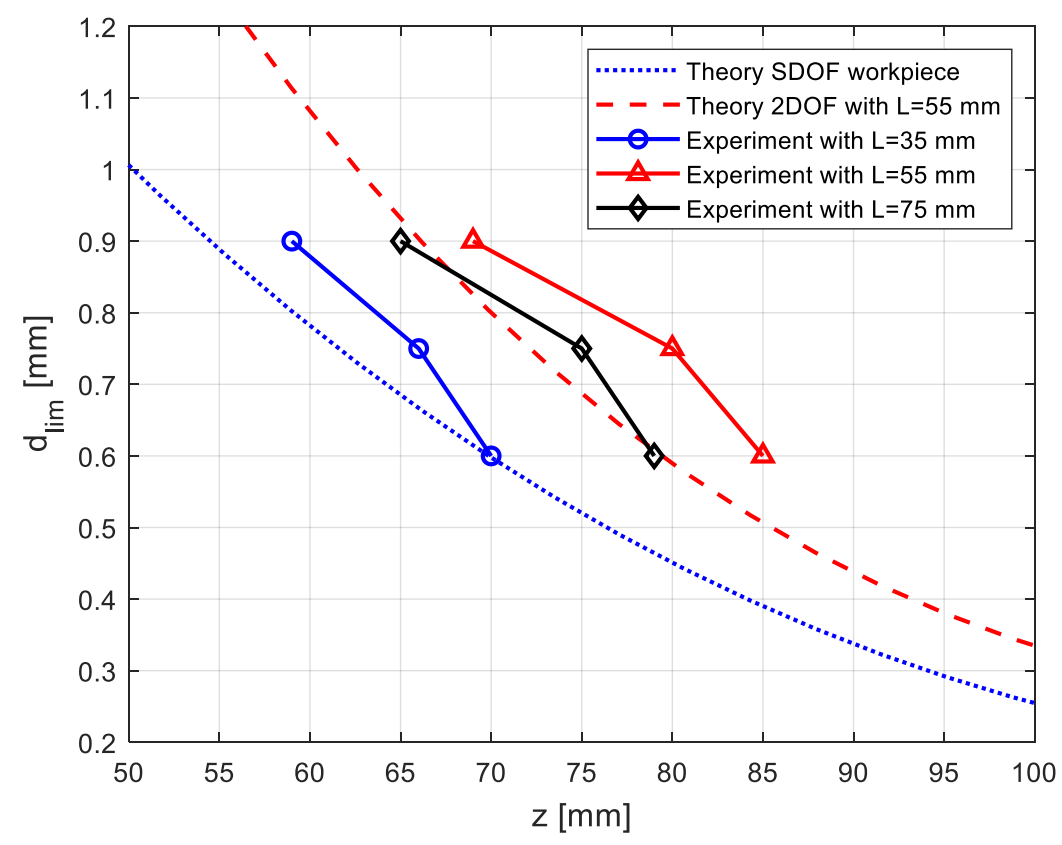

Fig. 18 Comparison of the theoretical and experimental chatter onset locations

\section{Conclusions}

In this study, a new perspective on chatter stability enhancement in turning of flexible workpieces is explored on the basis of stability analysis of the 2DOF tool-workpiece chatter model. The correlation between the dynamic characteristics of the machining system and chatter stability is deduced analytically. The effect of the coupling of dynamics of the tool and workpiece on the limiting $d o c, d_{\lim }$ , is investigated. As a result of the theoretical analysis, the tool dynamics adaption (TDA) approach is proposed to improve the stability. Furthermore, the experimental investigation of the compliant toolworkpiece system was also performed to verify the presented chatter suppression method. Based on the results of the theoretical and experimental analysis, key conclusions are drawn as follows.

(1) The presented 2DOF tool-workpiece chatter model is more compatible and closer to reality when compared with the conventional SDOF model. In particular, when the tool or the workpiece is much stiffer than its counterpart, the 2DOF model will be reduced to the SDOF model. The relationship 
between the $d_{\lim }$ and the dynamics of the 2DOF system allows the novel TDA approach to be implemented for enhancing the stability when cutting flexible workpieces.

(2) In the turning of low-rigidity workpieces, an inflection point generally exists on the cutting positiondependent $d_{\text {lim }}$ curve, beyond which increasing the stiffness in either workpiece or tool shows little improvement. An increase either in the tool flexibility or the workpiece damping can improve the machining stability. It is worth noting that the tool with its eigenfrequency close to that of the workpiece can reduce the process stability.

(3) In the machining experiments, the adjustable tool shank parallel to the cantilever workpiece is developed to materialize the analytical chatter model. It has been shown that the adaptive tool compliance in TDA can stabilize the cutting process of the flexible component, extending the chatter onset location more than $20 \%$. For industrial applications, the proposed method also provides an alternative solution to chatter control in robotic machining operations, where the inherently limited robot stiffness always influences machining quality.

\section{Acknowledgements}

The authors would like to thank Mr. Wenping Wang and Bin Shi for their professional assistance in the machining experiments. The support of National Natural Science Foundation of China under grant No. 51805352 and China Scholarship Council is also acknowledged.

\section{Conflict of Interest}

The authors declare that they have no conflict of interest. 


\section{References}

1. Siddhpura M, Paurobally R (2012) A review of chatter vibration research in turning. Int J Mach Tools Manuf 61:27-47

2. Munoa J, Beudaert X, Dombovari Z, Altintas Y, Budak E, Brecher C, Stepan G (2016) Chatter suppression techniques in metal cutting. CIRP Ann-Manuf Technol 65: 785-808

3. Rivin E, Karlic P, Kim Y (1990) Improvement of machining conditions for turning of slender bars by application of tensile force. Fundamental Issues in Machining, ASME PED 43:283-297

4. Guo J, Han R (2006) A united model of diametral error in slender bar turning with a follower rest. Int J Mach Tools Manuf 46:1002-1012

5. Lu K, Lian Z, Gu F, Jun H (2018) Model-based chatter stability prediction and detection for the turning of a flexible workpiece. Mech Syst Sig Process 100:814-826

6. Stepan G, Kiss AK, Ghalamchi B, Sopanen J, Bachrathy D (2017) Chatter avoidance in cutting highly flexible workpieces. CIRP Ann-Manuf Technol 66:377-380

7. Fischer A, Eberhard P, Ambrosio J (2014) Parametric flexible multibody model for material removal during turning. J Comput Nonlinear Dyn 9: 011007

8. Urbikain G, Fernández A, Lopez de Lacalle L, Gutiérrez ME (2013) Stability lobes for general turning operations with slender tools in the tangential direction. Int J Mach Tools Manuf 67:35-44

9. Lu K, Jing M, Zhang X, Dong G, Liu H (2015) An effective optimization algorithm for multipass turning of flexible workpieces. J Intell Manuf 26: 831-840

10. Lee E, Nian C, Tarng Y (2001) Design of a dynamic vibration absorber against vibrations in turning operations. J Mater Process Technol 108: 278-285

11. Sims ND (2007) Vibration absorbers for chatter suppression: A new analytical tuning methodology. J Sound Vib 301:592-607

12. Wang M, Zan T, Yang Y, Fei R (2010) Design and implementation of non-linear TMD for chatter suppression: an application in turning processes. Int J Mach Tools Manuf 50:474-479

13. Burtscher J, Fleischer J (2017) Adaptive tuned mass damper with variable mass for chatter avoidance. CIRP Ann-Manuf Technol 66:397-400

14. Tian L, Wu J, Xiong Z, Ding H (2015) Active chatter suppression in turning of low-rigidity workpiece by system matching. In: Proceedings of Intelligent Robotics and Applicatons- $8^{\text {th }}$ International Conference, ICITA 2015: 609-618

15. Urbikain G, Olvera D, Lópezde Lacalle LN, Elías-Zúñiga A (2016) Spindle speed variation technique in turning operations: modeling and real implementation. J Sound Vib 383:384-396

16. Sun Y, Xiong Z (2017) Modeling, analysis, and removal of chatter marks in flexible turning. Int J Adv Manuf Technol 93:4187-4196

17. Yilmaz A, Emad AR, Ni J (2002) Machine tool chatter suppression by multi-level random spindle speed variation. J Manuf Sci Eng 124: 208-216

18. Wang M, Fei R (1999) Improvement of machining stability using a tunable-stiffness boring bar containing an electrorheological fluid. Smart Mater Struct 8:511 
19. Mei D, T. Kong, Shih AJ, Chen Z (2009) Magnetorheological fluid-controlled boring bar for chatter suppression. J Mater Process Technol 209:1861-1870

20. Wang C, Zhang X, Liu Y, Cao H, Chen X (2018) Stiffness variation method for milling chatter suppression via piezoelectric stack actuators. Int J Mach Tools Manuf 124:53-66

21. Esfandi N, Tsao T(2017) Robot assisted machining of thin-walled structures. IFAC PapersOnLine 50:14594-14599

22. Otto A, Khasawneh FA, Radons G (2015) Position-dependent stability analysis of turning with tool and workpiece compliance. Int J Adv Manuf Technol 79:1453-1463

23. Chen CK, Tsao YM (2006) A stability analysis of turning a tailstock supported flexible workpiece. Int J Mach Tools Manuf 46(1):18-25

24. Vela-Martinez L, Jauregui-Correa JC, Rubio-Cerda E, Gilberto HR, Alejandro LG (2008) Analysis of compliance between the cutting tool and the workpiece on the stability of a turning process. Int J Mach Tools Manuf 48(9):1054-1062

25. Sekar M, Srinivas J, Kotaiah K, Yang S (2009) Stability analysis of turning process with tailstock-supported workpiece. Int J Adv Manuf Technol 43:862-871

26. Otto A, Rauh S, Kolouch M, Radons G (2014) Extension of Tlusty's law for the identification of chatter stability lobes in multi-dimensional cutting processes. Int J Mach Tools Manuf 82-83:50-58

27. Siddhpura M, Siddhpura A, Paurobally R (2017) Chatter stability prediction for a flexible toolworkpiece system in a turning process. Int J Adv Manuf Technol 92:881-896

28. Svinin V, Samsonov A, Savilov A, Pyatykh A (2018) Self-oscillation suppression when turning non-rigid shafts using spring tools and the spring headstock center, MATEC Web of Conferences 224: 01059

29. Tobias SA (1965) Machine Tool Vibration, Blackie and Sons Ltd, London

30. Zatarain M, Bediaga I, Muñoa J, Insperger T (2010) Analysis of directional factors in milling: importance of multi-frequency calculation and of the inclusion of the effect of the helix angle. Int $\mathrm{J}$ Adv Manuf Technol 47:535-542

31. Altintas Y (2012) Manufacturing Automation: metal cutting mechanics, machine tool vibrations, and CNC design, University Press Cambridge

32. Lorong P, Larue A, Duarte A (2011) Dynamic study of thin wall part turning. Adv Mater Res 223:591-599

33. Ritou M, Rabreau C, Loch S, Furet B, Numur D (2018) Influence of spindle condition on the dynamic behavior. CIRP Ann-Manuf Technol 67:419-422

34. Lu K, Wang Y, Gu F, Pang X, Ball A (2019) Dynamic modeling and chatter analysis of a spindleworkpiece-tailstock system for the turning of flexible parts. Int J Adv Manuf Technol 104:3007-3015

35. Jorgensen BR, Shin YC (1998) Dynamics of spindle-bearing systems at high speeds including cutting load effects, J Manuf Sci Eng 120: 387-394 